\title{
Efficient Nonlinear Companding Transform Scheme for Reducing PAPR of OFDM Signals
}

\author{
Xinguo Li \\ Shenzhen National Engineering Laboratory of Digital Television Co., Ltd., Shenzhen, China \\ Email:xgli@neldtv.org
}

How to cite this paper: Li, X.G. (2017) Efficient Nonlinear Companding Transform Scheme for Reducing PAPR of OFDM Signals. Int. J. Communications, Network and System Sciences, 10, 293-298. https://doi.org/10.4236/ijcns.2017.108B031

Received: July 21, 2017

Accepted: August 11, 2017

Published: August 14, 2017

\begin{abstract}
Efficient nonlinear companding transform (NCT) scheme for reducing peakto-average power (PAPR) of orthogonal frequency division multiplexing (OFDM) signals is proposed. This scheme transforms the Gaussian-distributed signals into the specified statistics form defined as a piecewise function. By adjusting the transform parameters, it enables more design flexibility in companding form so that a favorable trade-off between PAPR and bit error rate (BER) can be offered. Compared to existing techniques, the scheme can achieve an effective reduction in PAPR as well as an improved BER performance simultaneously.
\end{abstract}

\section{Keywords}

OFDM, PAPR, NCT, HPA

\section{Introduction}

Orthogonal frequency division multiplexing (OFDM) technique has been widely adopted in modern wireless communications due to its high spectral efficiency and immunity to the multipath fading effects. However, a critical drawback of OFDM system is the high peak-to-average power ratio (PAPR) of the transmitted signals. The high PAPR results in the in-band distortion and out-of-band interference when the nonlinear power amplifier (HPA) is utilized at the transmitter. Various PAPR reduction methods have been proposed for OFDM systems over the past decade [1], among which, the nonlinear companding transform (NCT) is perhaps the most attractive and significant method owing to its effectiveness and simplicity. NCT belongs to the category of signal pre-distortion solutions for PAPR reduction, and can be employed straightforwardly without any restriction on the OFDM system parameters.

NCT method was first introduced in [2], which used a law companding and 
can significantly outperform the conventional "hard" clippings. Nevertheless, its average output power is increased after the logarithmic-based compression, which makes itself ever more sensitive to the HPA. Later, the work of [3] pointed out the importance of taking into account the statistics of the companded signals. Recently, a variety of NCT schemes with better performances have been proposed, including the exponential companding (EC) [4], piecewise companding (PC) [5], and trapezoidal companding (TC) [6], etc. However, these schemes are limited under certain bit error rate (BER) performance constraint [7].

Both PAPR and moderate performance degradation are critical challenges for a well-designed companding scheme [8]. In order to obtain efficient PAPR reduction in OFDM systems, this paper proposes a new NCT scheme. By introducing the variable parameters and an inflexion point in the target probability density function (PDF), while remaining an unchanged average power level, the scheme can achieve an effective PAPR reduction as well as an improved BER performance simultaneously. Besides, it also allows more flexibility in the companding form so that a flexible trade-off between PAPR and BER can be offered. Analysis and simulations demonstrate its effectiveness.

\section{PAPR Formulation}

Suppose the complex-value vector $\mathbf{X}=\left[X_{0}, X_{1}, \ldots, X_{N-1}\right]^{T}$ denotes the frequency-domain OFDM symbol, where $N$ is the number of subcarriers. In the discrete case, the time-domain OFDM signal $\mathbf{x}=\left[x_{0}, x_{1}, \ldots, x_{N-1}\right]^{T}$ can be represented as

$$
x_{n}=\frac{1}{\sqrt{N}} \sum_{k=0}^{N-1} X_{k} e^{j \frac{2 \pi n k}{N}}, n=0,1, \ldots, N-1 .
$$

Based on the central limit theory, when $N$ is large, $x_{n}$ may be approximated as a complex Gaussian process with zero mean and a common variance $\sigma^{2}$. Thus, the signal amplitude $\left|x_{n}\right|$ follows a Rayleigh distribution with the $\mathrm{PDF}$ as

$$
f_{\left|x_{n}\right|}(x)=\frac{2 x}{\sigma^{2}} e^{-\frac{x^{2}}{\sigma^{2}}}, \quad x \geq 0 .
$$

The PAPR of OFDM signal in a given time-domain symbol is defined as

$$
\operatorname{PAPR}_{\mathbf{x}} \triangleq \frac{\max _{n \in[0, N-1]}\left\{\left|x_{n}\right|^{2}\right\}}{E\left\{\left|x_{n}\right|^{2}\right\}} \text {. }
$$

\section{Proposed Scheme}

In this section we first derive the generic formulas of the proposed scheme. Then, its theoretical performance is characterized with the achievable PAPR gain. The main idea of the scheme is to transform the statistics of the signal amplitude into a specified PDF form defined by a piecewise function with an inflexion point. Assume that the inflexion point and cutoff point of this target PDF are $c A(c \geq 0)$ and $A$, respectively. The specified PDF can be expressed as 


$$
f_{\left|y_{n}\right|}(x)=\left\{\begin{array}{ll}
x^{m}, & 0 \leq x \leq c A \\
k x+b, & c A<x \leq A
\end{array} .\right.
$$

where $m, k$ and $b$ are the transform parameters that control the companding form i.e. ultimate PAPR, while adjusting the average output power level in the operation. The target cumulative distribution function (CDF) can also be given by

$$
F_{\left|y_{n}\right|}(x)=\left\{\begin{array}{lc}
\frac{x^{m+1}}{m+1}, & 0 \leq x \leq c A \\
\frac{k}{2} x^{2}+b x+\frac{(c A)^{m+1}}{m+1}-\frac{k(c A)^{2}}{2}-b c A, & c A<x \leq A \\
1, & x>A
\end{array}\right.
$$

From the CDF definition, namely $F_{\left|y_{n}\right|}(A)=1$, we have

$$
k=\frac{2\left(1-c^{m} A^{m+1}\left(1-\frac{m c}{m+1}\right)\right)}{A^{2}(1-c)^{2}} \text {. Given that the proposed companding function }
$$

$C(x)$ is a strictly monotonic increasing function. Thus, it can be calculated according to following identity.

$$
C(x)=\operatorname{sgn}(x) F_{\left|y_{n}\right|}^{-1}\left[F_{\left|x_{n}\right|}(x)\right],
$$

where $\operatorname{sgn}(\cdot)$ denotes the sign function. The companding function is given by

$$
C(x)= \begin{cases}\operatorname{sgn}(x)\left\{(m+1)\left(1-e^{-\frac{|x|^{2}}{\sigma^{2}}}\right)\right\}^{\frac{1}{m+1}}, & |x| \leq \zeta_{0} \\ \operatorname{sgn}(x) \frac{1}{k}\left\{-b+\sqrt{b^{2}+2 k\left(1-e^{-\frac{|x|^{2}}{\sigma^{2}}}+b c A+\frac{k(c A)^{2}}{2}-\frac{(c A)^{m+1}}{m+1}\right)}\right\},|x|>\zeta_{0}\end{cases}
$$

where $\zeta_{0}=\sqrt{-\sigma^{2} \ln \left(1-\frac{(c A)^{m+1}}{m+1}\right)}$. The corresponding de-companding function is

$$
C^{-1}(x)= \begin{cases}\operatorname{sgn}(x) \sqrt{-\sigma^{2} \ln \left(1-\frac{\left|r_{n}\right|^{m+1}}{m+1}\right)}, & |x| \leq c A \\ \operatorname{sgn}(x) \sqrt{-\sigma^{2} \ln \left(-\frac{k}{2}\left|r_{n}\right|^{2}-b\left|r_{n}\right|+b c A+\frac{k(c A)^{2}}{2}-\frac{(c A)^{m+1}}{m+1}+1\right)}, & |x|>c A\end{cases}
$$

To reduce the implementation complexity, both functions in Equation (7) and Equation (8) can be numerically pre-computed and performed through the lookup tables in practice. Moreover, in order to keep the input and output signal with an unchanged power level, i.e. $E\left\{\left|y_{n}\right|^{2}\right\}=E\left\{\left|x_{n}\right|^{2}\right\}$, we can obtain

$$
b=\frac{3}{A^{3}\left(1-c^{3}\right)}\left\{\sigma^{2}-\frac{(c A)^{m+3}}{m+3}-\frac{k}{4} A^{4}\left(1-c^{4}\right)\right\} \text {. }
$$


Figure 1 depicts the companding and de-companding profiles of this scheme. As observed, by compressing large amplitude signals while enlarging small ones, both the PAPR reduction and immunity of small signals from noise can be achieved.

The ultimate PAPR of the companded signal with this scheme is given by

$$
\operatorname{PAPR}_{\mathbf{y}}=\frac{1}{k^{2} \sigma^{2}}\left\{-b+\sqrt{b^{2}+2 k\left(1-\mathrm{e}^{-\frac{A_{c}^{2}}{\sigma^{2}}}+b c A+\frac{k(c A)^{2}}{2}-\frac{(c A)^{m+1}}{m+1}\right)}\right\}^{2}
$$

where $A_{c}=\max _{0 \leq n \leq N-1}\left\{\left|x_{n}\right|\right\}$. Furthermore, the transform gain $\mathrm{G}$ is defined as the ratio of the PAPR of original signal to that of the companded signal [3], i.e.

$$
\mathrm{G}(\mathrm{dB})=20 \log _{10} \frac{k A_{c}}{-b+\sqrt{b^{2}+2 k\left(1-\exp \left(-\frac{A_{c}^{2}}{\sigma^{2}}\right)+b c A+\frac{k(c A)^{2}}{2}-\frac{(c A)^{m+1}}{m+1}\right)}} .
$$

According to Equation (11), the achievable G in PAPR is more than $7.7 \mathrm{~dB}$.

\section{Simulation Results}

In this section, we present numerical simulations to evaluate the performance of the proposed scheme. We consider an un-coded OFDM system with the number of subcarriers $N=1024$ and using quadrature phase-shift keying (QPSK) or 16-quadrature amplitude modulation (16QAM). Three other popular NCT schemes, i.e. the $\mu$-law $(\mu=31)$, EC $(d=1)$ and TC $(a=0.8, b=0.1)$ were also included for comparison. The oversampling factor was specified as $J=4$. The performance of PAPR-reduction technique is evaluated by the complementary CDF (CCDF) of the PAPR, which is defined as

$$
\mathrm{CCDF}_{\mathbf{y}}\left(\mathrm{PAPR}_{0}\right) \triangleq \operatorname{Prob}\left\{\operatorname{PAPR}_{\mathbf{y}}>\operatorname{PAPR}_{0}\right\}=1-\left(1-e^{-\mathrm{PAPR}_{0}}\right)^{N} .
$$

where $\mathrm{PAPR}_{0}>0$ is an assigned threshold. Figure 2 depicts the simulated
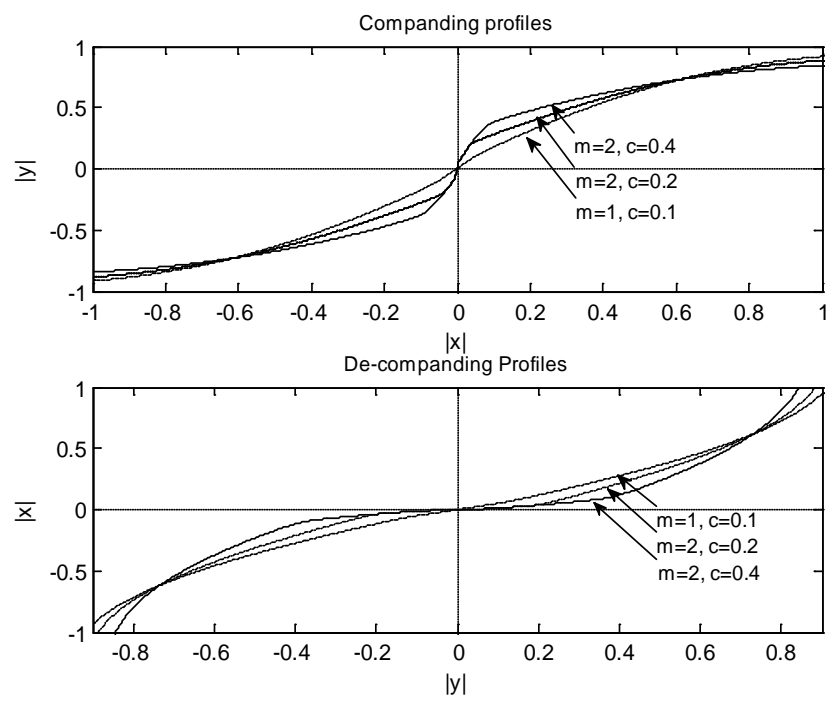

Figure 1. Companding and de-companding profiles. 
CCDFs of the PAPR with different schemes for QPSK. As shown in the figure, our scheme can effectively reduce the PAPR while simultaneously obtaining sharp drops in CCDFs.

Figure 3(a) and Figure 3(b) plot the BER versus $E_{b} / N_{0}$ curves with different

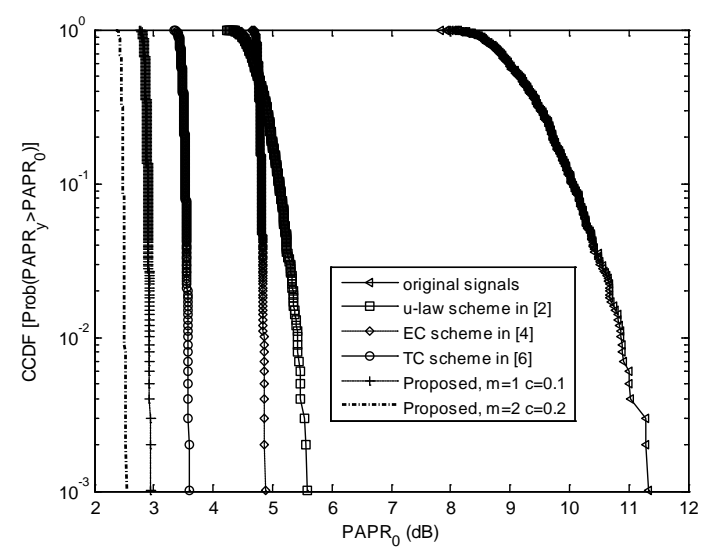

Figure 2. The CCDFs of the original and companded signals.

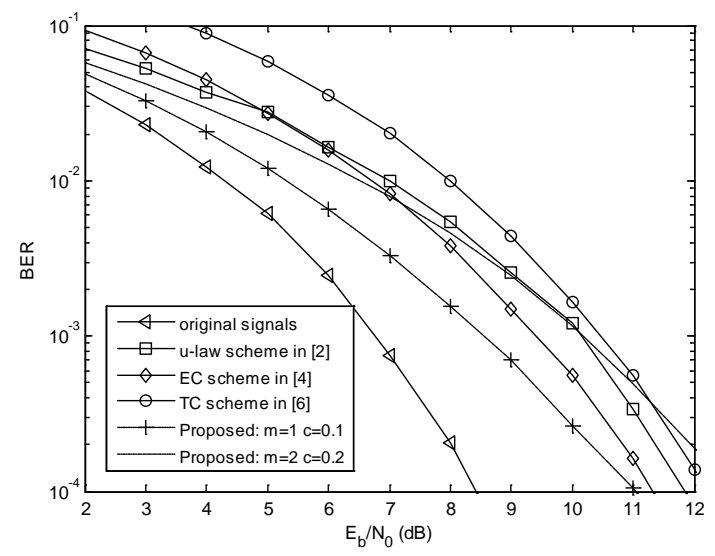

(a)

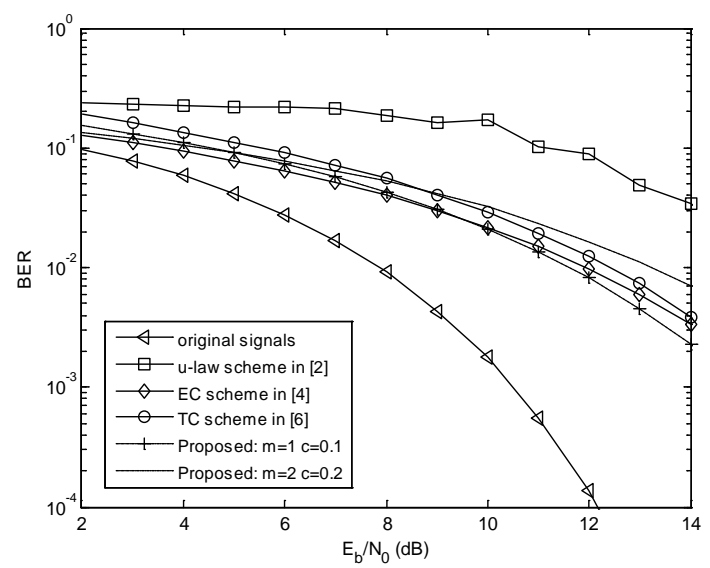

(a)

Figure 3. BER performance of different schemes over AWGN channel. 
schemes over the additive Gaussian white noise (AWGN) channel for QPSK and 16QAM, respectively. As observed, our scheme can obtain better BER performance than the referred schemes. For example, at BER $=10^{-4}$ for QPSK, the required $\mathrm{E}_{\mathrm{b}} / \mathrm{N}_{0}$ for our scheme with $m=1, c=0.1$ is roughly $0.2 \mathrm{~dB}$ to $1.4 \mathrm{~dB}$ superior to others. On the other hand, by adjusting the variable parameters, a favorable trade-off between PAPR and BER can be achieved to satisfy various requirements.

\section{Conclusion}

In this paper, we have proposed and evaluated a new NCT scheme. Both the theoretical analysis and simulations show that it offers an improved BER performance while reducing the PAPR significantly. Moreover, by properly adjusting the transform parameters, a favorable trade-off between PAPR and BER can also be obtained.

\section{References}

[1] Jiang, T. and Wu, Y. (2008) An Overview: Peak-to-Average Power Ratio Reduction Techniques for OFDM Signals. IEEE Trans. Broadcast., 54, 257-268. https://doi.org/10.1109/TBC.2008.915770

[2] Wang, X.B., Tjhung, T.T. and Ng, C.S. (1999) Reduction of Peak-to-Average Power Ratio of OFDM System Using a Companding Technique. IEEE Trans. Broadcast., 45, 303-307. https://doi.org/10.1109/11.796272

[3] Huang, X., Lu, J., Zheng, J., Letaief, K.B. and Gu, J. (2004) Companding Transform for Reduction in Peak-to-Average Power Ratio of OFDM Signals. IEEE Trans. Wireless Commun., 3, 2030-2039. https://doi.org/10.1109/TWC.2004.837619

[4] Jiang, T., Yang, Y. and Song, Y. (2005) Exponential Companding Transform for PAPR Reduction in OFDM Systems. IEEE Trans. Broadcast., 51, 244-248. https://doi.org/10.1109/TBC.2005.847626

[5] Hou, J., Ge, J.H. and Li, J. (2009) Trapezoidal Companding Scheme for Peak-toAverage Power Ratio Reduction of OFDM Signals. Electron. Lett., 45, 1349-1351. https://doi.org/10.1049/el.2009.2180

[6] Hou, J., Ge, J., Zhai, D. and Li, J. (2010) Peak-to-Average Power Ratio Reduction of OFDM Signals with Nonlinear Companding Scheme. IEEE Trans. Broadcast., 56, 258-262. https://doi.org/10.1109/TBC.2010.2046970

[7] Wang, Y., Wang, L.-H. and Ge, J.-H. (2012) An Efficient Nonlinear Companding Transform for Reducing PAPR of OFDM Signals. IEEE Trans. on Broadcasting, 58, 677-684. https://doi.org/10.1109/TBC.2012.2198976

[8] Wang, Y., Ge, J.-H. and Wang, L.-H. (2013) Nonlinear Companding Transform for Reduction of PEAK-to-Average Power Ratio in OFDM Systems. IEEE Trans. on Broadcasting, 59, 369-375. https://doi.org/10.1109/TBC.2012.2219252 
Submit or recommend next manuscript to SCIRP and we will provide best service for you:

Accepting pre-submission inquiries through Email, Facebook, LinkedIn, Twitter, etc. A wide selection of journals (inclusive of 9 subjects, more than 200 journals)

Providing 24-hour high-quality service

User-friendly online submission system

Fair and swift peer-review system

Efficient typesetting and proofreading procedure

Display of the result of downloads and visits, as well as the number of cited articles Maximum dissemination of your research work

Submit your manuscript at: http://papersubmission.scirp.org/

Or contact ijcns@scirp.org 